www.jmscr.igmpublication.org

Impact Factor 5.84

Index Copernicus Value: 83.27

ISSN (e)-2347-176x ISSN (p) 2455-0450

crossref DOI: _https://dx.doi.org/10.18535/jmscr/v5i4.11

\title{
Post Cholecystectomy Stump Calculus Cholecystitis with Completion Cholecystectomy -A Rare Case Report
}

\author{
Authors \\ Dr Shrirang Yadwadkar ${ }^{1}$, Dr Rajiv Chnadra ${ }^{2}$, Dr Manish Motwani ${ }^{3}$, Dr Jayant ${ }^{4}$, \\ Dr Swapnali ${ }^{5}$ \\ ${ }^{1}$ SMC (Speciality Medical Consultant), Dept of Surgery, ${ }^{2,3}$ Assistant Honorary, Dept of Surgery, \\ ${ }^{4}$ SMO (Speciality Medical Officer), Dept of Surgery \\ ${ }^{5}$ SMC (Speciality Medical Consultant), Dept of Anaesthesia \\ M.T. Agrawal Hospital, Opposite ESIS Hospital, Off LBS Road, \\ Mulund - (West), Mumbai-400080 Maharashtra \\ *Corresponding Author \\ Dr Shrirang Yadwadkar \\ * Address - M.T. Agrawal Hospital, Opposite ESIS Hospital, Off LBS Road, Mulund \\ (West), Mumbai-400080 Maharashtra \\ Email: yadwadkarshrirang@gmail.com,Phone No:08855022933
}

\begin{abstract}
Cholecystectomy is the most common method of choice for treating symptomatic gall stones. It can either be performed laproscopically or by open cholecystectomy. Partial cholecystectomy is usually done whenever there is difficulty in performing total cholecystectomy due to various reasons such as acute attack with adhesions, fibrosis, in view of preventing bile duct and vascular injuries, variations in anatomy which lead to bile duct remnant which can cause post cholecystectomy syndrome. After a partial or subtotal cholecystectomy, symptoms may recur from pathology in the gallbladder remnant. When this occurs, a completion cholecystectomy is required as treatment of choice.

We here report a case of a patient with stump cholecystitis in a gallbladder remnant to demonstrate open exploratory laparotomy with completion cholecystectomy.

Keywords: Cystic duct stump calculi, stump cholecystitis, completion cholecystectomy.
\end{abstract}

\section{Introduction}

Cholecystectomy, either laparoscopically or by the conventional 'open' method, is considered to be the "gold standard" operation for gallstones ${ }^{[1]}$. Partial cholecystectomy has been performed in many situations such as difficult Calot's triangle, where the anatomy may be distorted by recurrent episodes of inflammation, adhesions or bleeding. In such a situation, persisting with dissection in the calot's triangle can lead to major complications such as common bile duct and/or vascular injury, which can turn the procedure into a nightmare, both for the surgeon as well as the patient. In such cases, it is advisable to leave a 
cuff of the gallbladder near the Hartmann's pouch, removing the rest of the gallbladder, in the manner described by Lerner [2] or Bornman and Terblanche ${ }^{[3]}$ after removing all stones from the remaining cuff of the gallbladder. However, this carries the risk of developing stump cholecystitis when the gallbladder remnant becomes inflamed due to stone disease ${ }^{[4]}$. The reported incidence of stump cholecystitis varies but has been reported to occur in as many as 5\% ${ }^{[4]}$ of patients after emergent cholecystectomy, and it is rare after elective operations. It tends to occur in middleaged women who are usually quite confident that their symptoms are similar to those that prompted their original cholecystectomy. The diagnosis is always into the dilemma as history suggestive of symptoms of post cholecystectomy syndromes leading to delayed diagnosis. Contrast enhanced CT scan or MRCP further aids in definitive diagnosis. ERCP can help in the diagnosis and if possible stones in the cystic duct remnant can be taken out with great difficulty. Most of the patients with retained calculi require surgical intervention and re exploration to remove the cystic duct remnant and stones.

\section{Case Report}

45-year-old man with hypertension presented to our hospital complaining of severe right upper quadrant pain and vomiting. He reported having laparoscopic cholecystectomy done eight years before followed by biliary leak with cystic duct stump blow out for which Exploratory laparotomy done with ERCP and CBD stenting done. Now he noted that the symptoms he now experienced were similar. He had been hospitalized four times in the preceding two years for similar episodes. Although abdominal ultrasounds were done on these occasions, the emergency room physicians did not entertain the possibility of a stump cholecystitis because the patient insisted that her gallbladder had already been removed.

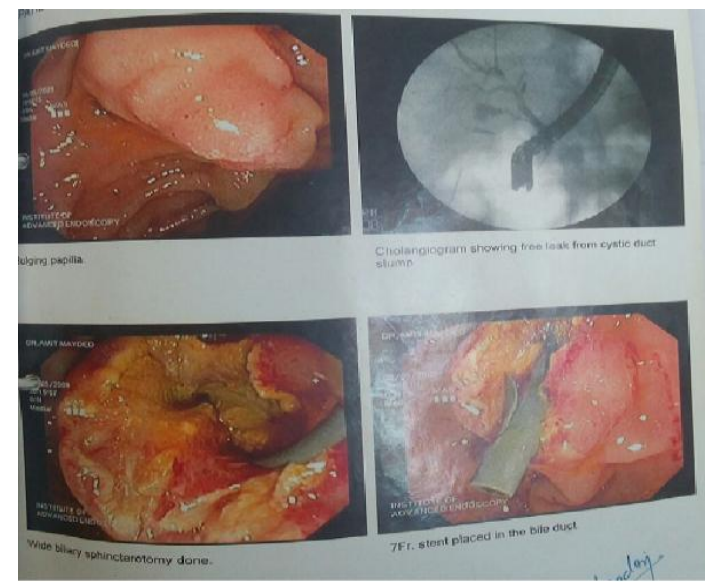

Figure 1. Previous ERCP with cystic duct leak and stent placement

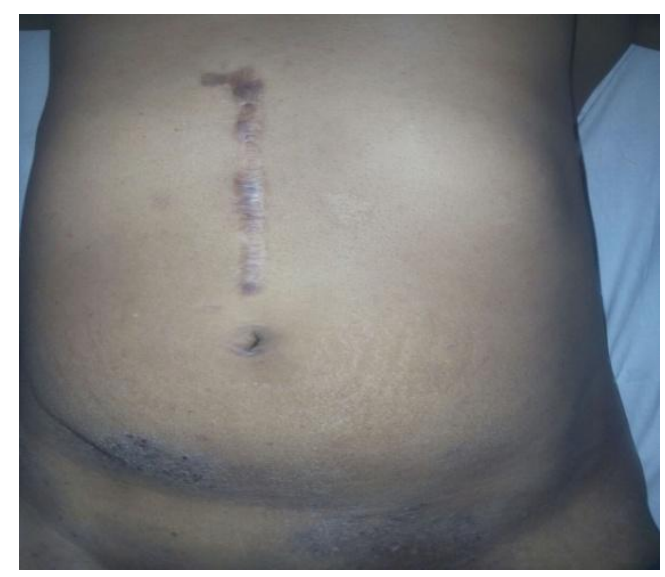

Figure 2. Previous laparotomy scar

Abdominal ultrasound suggested that stones were present in a thick walled remnant of gall bladder with no evidence of dilated CBD.MR cholangiography revealed Gll bladder stump with calculus and sludge within and associated with wall thickening suggestive of stump cholecystitis. Exploratory laparotomy done with completion cholecystectomy with removal of multiple remnant stones and part of gallbladder with cystic duct. Wound closure done with drain in situ.Post operative course was uneventful. Drain removal done on $5^{\text {th }}$ day followed by stitch removal on $10^{\text {th }}$ day. 6 month follow up of the patient done without any new complaint. 


\section{JMSCR Vol||05||Issue||04||Page 19782-19786||April}

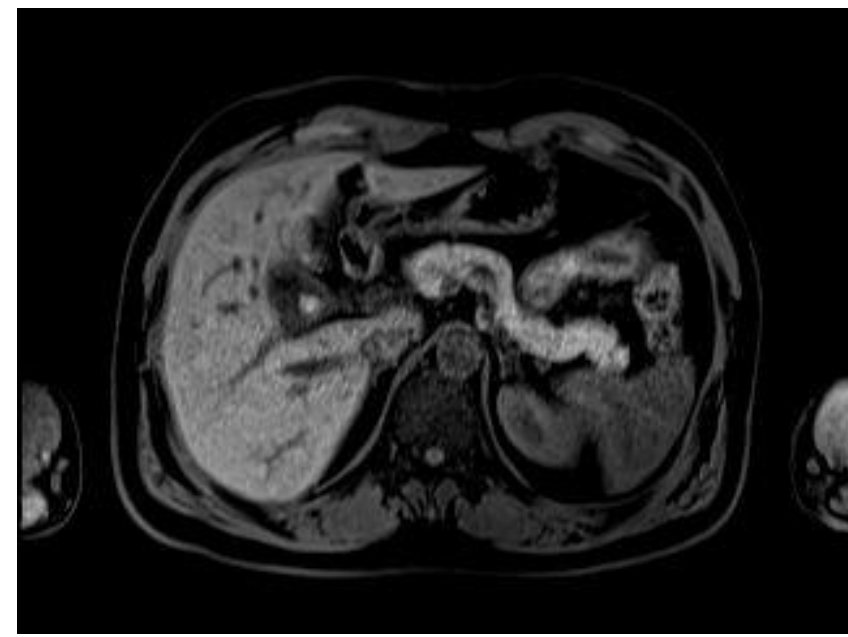

Figure 3 MR cholangiography showing Gall bladder remnant with calculi

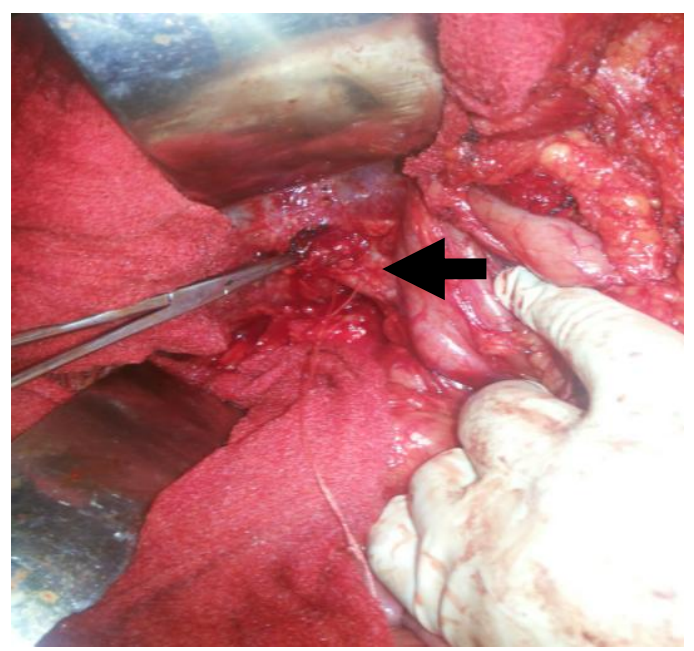

Figure 3 .Cystic duct remnant

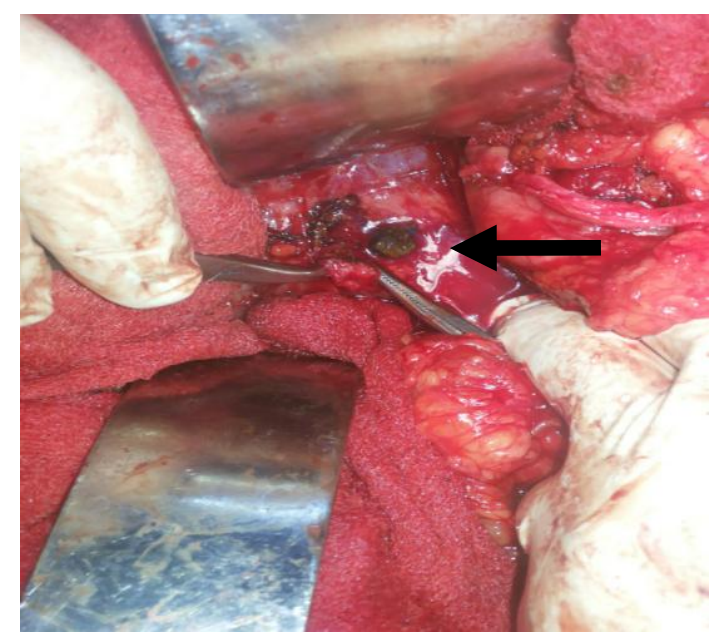

Figure 4. Cystic duct stump with calculus

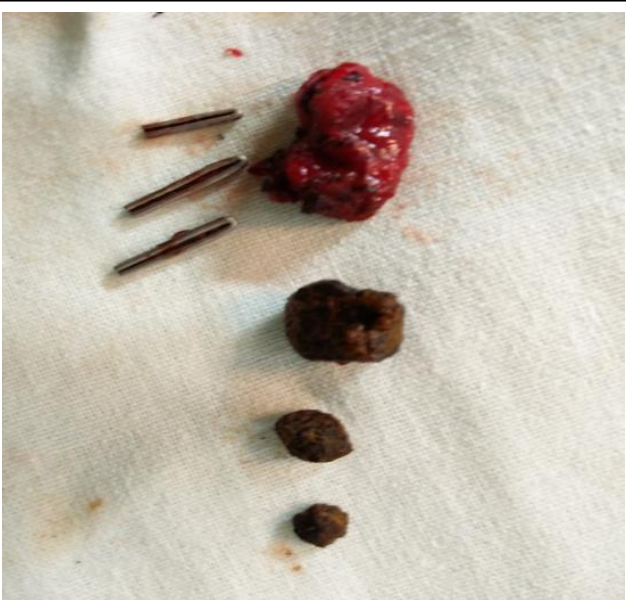

Figure 5 Cystic duct remnant with stones

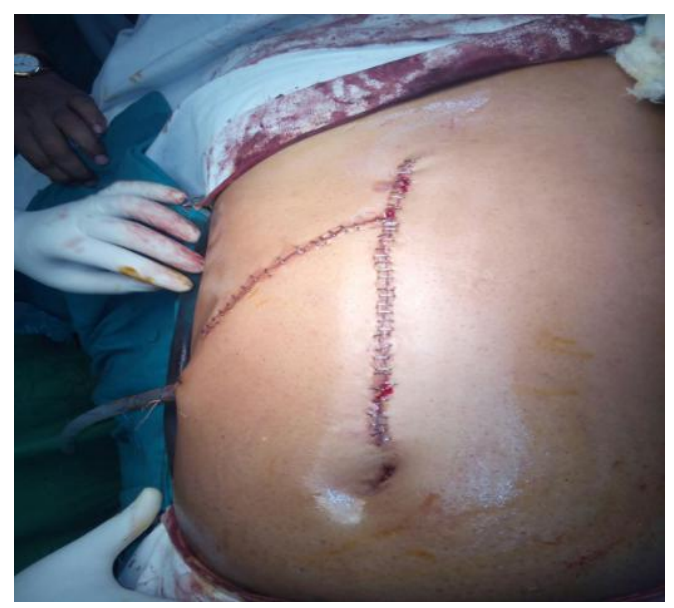

Figure 6. Post operative wound with previous applied clips

\section{Discussion}

\section{Imaging Anatomy}

The normal cystic duct connects the gall bladder to the common hepatic duct to form the common bile duct, and is considered the most important structure to be identified during cholecystectomy. The normal cystic duct usually measures $46 \mathrm{~cm}$ in length and contains concentric folds known as the spiral valves of Heister. ${ }^{[5]}$ Cystic ducts shorter than $2 \mathrm{~cm}$ can also be found, which can present a significant challenge in the dissection and placement of clips during laparoscopic cholecystectomy. The diameter of the cyst

duct ranges from 1 to $5 \mathrm{~mm}$. The cystic duct usually joins the extra hepatic bile duct approximately halfway between the port a hepatis and ampulla of vater, commonly to its medial aspect ${ }^{[6]}$. During cholecystectomy, a variable length of the cystic duct is left as a remnant. 
Usually, a cystic duct remnant measuring $12 \mathrm{~cm}$ in length is left, although remnants can be seen up to $6 \mathrm{~cm}$ in length. Complications associated with the remnant cystic duct are retained stones in cystic duct, bile leakage, stricture, fistula formation, dilatation of the cystic duct remnant, amputation neuromas, and suture granuloma of the cystic duct. Cystic duct mucocele is a rare complication, where the remnant of the cystic duct is distended with mucus. ${ }^{[5,6]}$

\section{Discussion}

By definition, any length of cystic duct more than or equal to $1 \mathrm{~cm}$ remaining following surgery is considered as a cystic duct remnant ${ }^{[7]}$. Bodvall and Overgaard found that a cystic duct remnant larger than $1 \mathrm{~cm}$ was present in $67 \%$ of patients with common bile duct stones and $82 \%$ of patients with severe postoperative biliary distress ${ }^{[8]}$. Rozses et al. reported the cause of post cholecystectomy syndrome to be due to the cystic duct stump syndrome in $16 \%$ of patients ${ }^{[9]}$. Though the exact incidence is not known, cystic duct or gall bladder remnant with or without stones seems to be emerging as one of the leading causes of post cholecystectomy syndrome, especially in this era of minimally invasive surgery where subtotal cholecystectomy has started gaining popularity ${ }^{[10,11]}$. The terminal end of the cystic duct remnant is described as resembling a "leaf bud" in normal post cholecystectomy patients. When the remnant is pathologically dilated, it is described as having the appearance of a "flashlight bulb". ${ }^{[12]}$ The dilatation or the pouch formation of the cystic duct remnant is thought to be due to an inflammatory reaction. Stump cholecystitis is rare phenomenon and in addition to it stump cholecystitis due to cystic duct stones is rare. It is not clear from the existing literature as to what is the natural history of these gallbladder remnants over a period of time, but there seems to be a trend towards surgical intervention in symptomatic patients. It could be concluded that the presence of a long cystic duct stump or a gallbladder remnant (with or without calculi) on investigation, in patients with persistent post-cholecystectomy symptoms definitely demands surgical intervention, especially when a stone is present ${ }^{[13,14,15]}$. Patients with gall bladder remnant can be asymptomatic or they can present with acute symptoms (biliary colic, acute cholecystitis or acute pancreatitis) or chronic symptoms (persistent right upper quadrant discomfort or pain, food intolerance, nausea or jaundice ${ }^{[16]}$. Although there are no pathognomic symptoms, the persistence of symptoms after cholecystectomy should alert the clinician to the possibility of a gallbladder remnant, especially when coupled with radiation of pain to the shoulder, food intolerance, nausea or jaundice ${ }^{[16,17]}$. Ultrasonography is the initial investigation followed by Contrast enhanced CT scan and MRCP. ERCP is recommended only in situations where some intervention is contemplated. The treatment of patients with gallbladder remnants who are symptomatic is excision of the remnant — the so-called "re-cholecystectomy", or "completion cholecystectomy ${ }^{[18]}$. Completion cholecystectomy can be done by open or laparoscopic. Due to previous difficult partial cholecystectomy or due to recurrent episode of inflammation, laparoscopic completion cholecystectomy can be converted into open.

\section{Conclusion}

Post cholecystectomy stump calculus cholecystitis is an important but rare sequelae after cholecystectomy. Completion cholecystectomy (open or laparoscopic) is the most common treatment modality reported in the literature for the management of residual gallbladder stump with stones.

\section{References}

1. Mayank Jayant, Robin Kaushik. Presentation and management of gallbladder remnant after partial cholecystectomy; Tropical Gastroenterology 2013 Apr-Jun;34(2):99-10. 
2. Lerner AI. Partial cholecystectomy. Can Med Assoc J. 1950;63:54-6.

3. Bornman PC, Terblanche J. Subtotal cholecystectomy: for the difficult gallbladder in portal hypertension and cholecystitis. Surgery. 1985;98:1-6

4. A. K. Parmar,R.G.Khandelwal, M. J. Mathew, and P. K. Reddy, "Laparoscopic completion cholecystectomy: a retrospective study of 40 cases," Asian Journal of Endoscopic Surgery, vol. 6, no. 2, pp. 96-99, 2013.

5. Turner MA, Fulcher AS. The cystic duct normal anatomy and disease processes. Radiographics. 2001;21:3-22. [PubMed]

6. Sherwinter DA, Subramanian SR, Cummings LS, Malit MF, Fink SL, Macura JM, et al. Cholecystectomy, Laparoscopic: emedicine. [Lastaccessed on 2010 Jul 16]. Available from: http://www.emedicine.medscape.com/artic le/1582292overview

7. Sitenko VM, Nechai AI, Stukalov W, Kalashnikov SA. Large stump of the cystic duct. Vestn Khir Im I I Grek. 1976;116:56-9. [PubMed]

8. Bodvall B, Overgaard B. CF duct remnant after cholecystectomy: incidence studied by cholegraphy in 500 cases, and significance in 103 reoperations. Ann Surg. 1966;163:382-5. [PMC free article] [PubMed]

9. Rozses I, Magyarodi Z, Orban P. Cystic duct syndrome and minimally invasive surgery. Orv Hetil. 1997;138:2397-401. [PubMed]

10. Lum YW, House MG, Hayanga AJ, Schweitzer M. Postcholecystectomy syndrome in the laparoscopic era. $\mathbf{J}$ Laparoendosc Adv Surg Tech A. 2006;16:482-5. [PubMed]

11. Chow M, von Waldenfels A, Pace R. An unusual case of a retained stone following laparoscopic cholecystectomy. J Laparoendosc Surg.1993;3:513-8. [PubMed]

12. Price EA. The radiology of bile ducts. Br J Radiol. 1959;32:247-54.

13. Hussain M, Nagral S. Biliary pancreatitis secondary to stones from a gall bladder remnant. Tropical Gastroenterology. 2010;31:230-3.

14. Selvaggi F, Di Bartolomeo N, De Iuliis I, Del Ciotto N, Innocenti P. Laparoscopic treated so-called reformed gallbladder in patient with postcholecystectomy chronic pain. G Chir. 2011;32:335-7.

15. Rogy MA, Függer R, Herbst F, Schulz F. Reoperation after cholecystectomy. The role of the cystic duct stump. HPB Surg. 1991;4:129-35

16. Whitson BA, Wolpert SI. Cholelithiasis and cholecystitis in a retained gallbladder remnant after cholecystectomy. J Am Coll Surg. 2007;205:814-15.

17. Calhoun SK, Piechowiak RL. Recurrent cholecystitis and cholelithiasis in a gallbladder remnant 14 years after a converted cholecystectomy. RCR. 2010;5 DOI: $10.2484 /$ rcr.v5i1.33.

18. Chowbey PK, Bandyopadhyay SK, Sharma A, Khullar R, Soni V, Baijal M. Laparoscopic reintervention for residual gallstone disease. Surg Laparosc Endosc Percutan Tech. 2003;13:31-5. 